\title{
INPUT-OUTPUT ANALYSIS OF RELATIONSHIPS BETWEEN THE AUSTRALIAN ECONOMIC SYSTEM AND WASTE MANAGEMENT
}

\author{
HE HE \\ (Received 4 June 2018; first published online 4 October 2018)
}

2010 Mathematics subject classification: primary 93D25.

Keywords and phrases: input-output approaches, waste management, economic activity.

How do Australian economic activities affect the waste management system? The objective of this thesis was to find measurement methods to answer this question. Australian economic activities are the main source of waste generation and understanding waste flows is the core of waste management. This can assist in the analysis of the origins of waste generation, waste generation characteristics and waste treatment capacities. There is a major stumbling block in the economic waste debate. Previously, it has been strongly suggested that the successful development of the economy normally depends on the production and use of more resources whilst the minimisation of waste must make and use less. Therefore, Australia must have a comprehensive and accurate quantification of waste flows and better analysis of relationships between the economy and waste management to illustrate how to overcome this blockage. This will allow greater understanding of the current and future economic conditions and ultimately allow the formulation of effective waste management strategies.

In this thesis, I first applied a waste input-output (WIO) model to analyse relationships between the Australian economy and waste flows. Then I devised an experiment to explore the forecasting ability of the WIO model. The effects of different types of household consumption on Australian economic activities and waste generation were discussed based on the application of the WIO model. Further discussions regarding the effects of household consumption as an endogenous factor were conducted according to a novel model, the closed waste supply-use table (CWSUT). Finally, I performed a comparative analysis between open and closed Australian waste supply-use tables as well as time-series CWSUTs.

Thesis submitted to the University of South Australia in May 2017; degree awarded on 28 January 2018; supervisor John Boland.

(C) 2018 Australian Mathematical Publishing Association Inc. 
The Australian WIO table in 2009-2010 was constructed according to the existing Australian input-output (IO) table and waste accounts in 2009-2010. However, the Australian WIO table in 2010-2011 was missing, so it was estimated using two steps. The first step estimated the Australian IO table in 2010-2011 by interpolation of the series of Australian IO tables from 2006-2007 to 2011-2012. The second step linked the Australian IO table in 2010-2011 with waste accounts in this year to build the Australian WIO table in 2010-2011. A comparative analysis of these two years' Australian WIO tables showed that as the total outputs of intermediate sectors increased, the amount of waste generated by the total outputs decreased. This not only indicated that the Australian economy was moving from a linear economy to a circular economy from the perspective of waste management, but also illustrated that the Australian waste policies published during the period have played an important role in waste reduction.

The application of the RAS method for data reconciliation based on the input coefficients and Leontief matrix in 2009-2010 and 2010-2011 to project the monetary WIO (MWIO) in 2012-2013 showed that the indicator of forecasting accuracy of mean absolute deviation in four scenarios was lower than $30 \%$. These four scenarios represent a combination of two different years' input coefficient matrices and two types of weights of physical flows for the landfill and recovery sectors. This indicated that the application of the RAS method in the WIO model was reliable for the projection of the MWIO model in future years. In addition, the forecasting accuracy based on the base year 2010-2011 was greater than that in 2009-2010. This illustrated that when the input coefficient matrix of the base year is closer than that of the target year, the forecasting accuracy of the WIO model will be higher.

I combined the input coefficients and Leontief matrix of the Australian WIO model with data regarding household consumption and waste collection on-site to explore the differences of the Australian economic activities and waste flow caused by different Australian household types. Results showed that the all other industry (AOI) sector inputted the highest amount of funds to other intermediate sectors, and the total waste generated in the Australian economic system for two types of households (D16 and B05) was more than that generated on-site. The former result showed that the AOI sector was the most significant sector for satisfying household consumption. The latter illustrated that waste policy makers should pay more attention to the supply chain to tackle waste generation by household consumption.

An Australian CWSUT was developed in 2009-2010 to illustrate the relationships between the Australian economy and waste management by considering household consumption as an endogenous factor of the Australian economy. The direct, indirect and total waste generation effects of intermediate sectors and waste treatment sectors as well as the economic costs of waste treatment sectors were shown to illustrate the relationships. Two comparative analyses of the CWSUTs in 2009-2010 and 20102011 as well as open and closed WSUTs in 2009-2010 were conducted. The first comparative analysis showed that the household sector played a more significant role in waste generation in 2010-2011 than in 2009-2010. The second indicated that the 
CWSUT can better analyse the effects of household consumption on the Australian economy and waste flows. In conclusion, the combination of the Australian inputoutput tables and waste accounts in WIO analysis illustrated the effects of Australian economic activity and environmental policies on waste management.

The structural decomposition analysis has been applied in a time-series Australian environmental (waste) input-output model from 2007-2008 to 2013-2014 to identify effects of driving forces (such as waste intensity, technology effect and final demand) on waste generation. The level effect of the final demand plays the most important role in waste generation during the period. Although the application of more ecological technologies has led to the decrease of waste generation, it cannot diminish the growth of waste generation caused by the final demand. Therefore, in order to lower waste generation and lessen environmental burden, it is not enough only to consider the application of the new technologies, but pay more attention on how to reduce the demand of the society.

The thesis has a comprehensive view of the dynamic analysis between the economic activities and waste flow. The major limitation is the lack of the availability of economic and waste data, which hinders the construction and application of the WIO model.

This study suggests three areas for future research:

- the development of time-series WIO analysis;

- the application of the CWSUT to other environmental issues;

- a comparative analysis of different territories' waste management by the application of Australian multi-regional CWSUTs.

HE HE,

School of Information Technology and Mathematical Sciences,

University of South Australia, Mawson Lakes,

South Australia 5095, Australia

e-mail: he.he@mymail.unisa.edu.au 